\title{
HIGH AFFINITY CHOLINE UPTAKE AND CALCIUM-DEPENDENT ACETYLCHOLINE RELEASE IN PROTEOLIPOSOMES DERIVED FROM RAT COPTICAL SYNAPTOSOMES ${ }^{1}$
}

\author{
EDWIN M. MEYER* AND JACK R. COOPER $\ddagger^{2}$ \\ ${ }^{*}$ Pharmacology Department, University of Florida Medical School, Gainesville, Florida 32610 and $\ddagger$ Department of \\ Pharmacology, Yale University School of Medicine, New Haven, Connecticut 06510
}

Received July 29, 1982; Revised November 8, 1982; Accepted November 30, 1982

\begin{abstract}
Proteoliposomes were prepared from rat cortical synaptic plasma membranes that retained high and low affinity choline transport. High affinity transport was inhibited by hemicholinium-3 in a competitive manner and was apparently dependent on membrane potential or ion gradients. Proteoliposomes supplemented with an acetylcholine-generating system were able to synthesize $\left[{ }^{3} \mathrm{H}\right] \mathrm{ACh}$ de novo from $\left[{ }^{3} \mathrm{H}\right]$ choline taken up by high or low affinity transport; however, we were able to specifically load proteoliposomes derived from cholinergic membranes by using a low choline concentration. $\left[{ }^{3} \mathrm{H}\right] \mathrm{ACh}$, but not $\left[{ }^{3} \mathrm{H}\right]$ choline, was subsequently released in a calcium-dependent manner by $\mathrm{K}^{+}$depolarization. This preparation offers a simplified membrane system for studying functional high affinity choline transport and nonvesicular ACh release.
\end{abstract}

A growing body of neurochemical evidence argues against an exocytotic mechanism for acetylcholine release. Even morphological experiments, which offer the major support for vesicular ACh release, have yielded conflicting data (for reviews, see Tauc, 1979; Israel et al., 1979; Cooper et al., 1982). Because it is not difficult to raise counterarguments to either neurochemical or morphological interpretations, primarily because of possible methodological artifacts, we have chosen to investigate the problem by two different approaches. The first was to use an antimony analog of choline (Sh replacing $\mathrm{N}$ ) to determine the localization and site of release of antimony-ACh via x-ray microanalysis coupled to electron microscopy (Meyer et al., 1981, 1982a). The second tack, described here, was to prepare proteoliposomes from synaptic plasma membranes that are devoid of synaptic vesicles and then determine if $\mathrm{ACh}$ could be released from them in a calcium-dependent manner. In order to prepare cholinergically active proteoliposomes, we developed a reconstituted synaptic plasma membrane preparation that retained the high affinity choline transporter. This reconstituted transporter was similar kinetically and pharmacologically to the transporter in intact synaptosomes (Meyer and Cooper, 1982). Furthermore, this report demonstrates that the high affinity choline trans-

\footnotetext{
${ }^{1}$ We wish to thank Rose Schulz for performing the electron microscopy. This work was supported by Public Health Service Grant NS 09836.

${ }^{2}$ To whom correspondence should be addressed.
}

porter can be used to preferentially load cholinergically derived proteoliposomes, that choline taken up by this preparation can be acetylated by an acetylcholine-generating system, and that the newly synthesized acetylcholine may be released in a calcium-sensitive manner.

\section{Materials and Methods}

Tissue preparations. Synaptosomes were prepared as described previously (Sgaragli et al., 1977) from the cerebral cortices of adult, male, Sprague-Dawley albino rats (Charles River Laboratories, Wilmington, MA). The synaptosomal pellet was suspended in $0.32 \mathrm{M}$ sucrose $(10 \mathrm{mg}$ of protein/ml, pH 7.4) after the Ficoll gradient density centrifugation.

Proteoliposomes containing synaptosomal plasma membrane fragments were prepared as follows. Synaptosomes in $0.32 \mathrm{M}$ sucrose were diluted 20 -fold with a solution of $150 \mathrm{~mm} \mathrm{KCl}, 1 \mathrm{~mm}$ HEPES (pH 7.6), and 5 $\mathrm{mM} \mathrm{MgCl}$, and they were then frozen in a dry ice-acetone bath. After thawing in a water bath at room temperature, tissues were frozen and thawed a second time. Next they were homogenized with a Teflon pestle and mortar $(0.25$ $\mathrm{mm}$ clearance). After a $20,000 \times g$ centrifugation for 10 min, the pellet was suspended in $100 \mu \mathrm{l}$ of $0.32 \mathrm{M}$ sucrose (pH 7.4) to give a protein concentration of 5 to $10 \mathrm{mg}$ of protein $/ \mathrm{ml}$. Neither ACh nor norepinephrine were recovered in this suspension, suggesting that synaptic vesicles were separated from the plasma membranes during this procedure. The sucrose suspension was diluted 10- 
fold with the $\mathrm{KCl} / \mathrm{HEPES} / \mathrm{MgCl}_{2}$ buffer described above, or, in some experiments, with a similar buffer in which the $\mathrm{KCl}$ was replaced with $\mathrm{NaCl}$. Sodium deoxycholate $(0.5 \%$ final concentration), azolectin-derived phosphatidylcholine (2 mg/ml; Sigma Chemical Co., St. Louis, MO), and dithiothreitol $(0.1 \mathrm{~mm}$ final concentration) were added sequentially to the suspension, which was next sonicated for $30 \mathrm{sec}$ (unless otherwise specified) with a Braun 1510 sonicator and microprobe tip (100 watts) at room temperature. Following sonication, samples were left at room temperature.

In some experiments, an acetylcholine-generating system was added to the preparation prior to sonication. This consisted of $0.2 \mathrm{mg} / \mathrm{ml}$ of choline acetyltransferase, $200 \mu \mathrm{M}$ CoA, $200 \mu \mathrm{M}$ acetylphosphate (each from Sigma Chemical Co.), $10 \mu \mathrm{g} / \mathrm{ml}$ of phosphotransacetylase (Boehringer-Mannheim), and $50 \mu \mathrm{M}$ eserine.

Proteoliposomes were formed by dialyzing the tissuedetergent-phosphatidylcholine suspension (plus or minus the acetylcholine-generating system) against the same $\mathrm{KCl} / \mathrm{HEPES} / \mathrm{MgCl}_{2}$ (KCl buffer) or $\mathrm{NaCl} / \mathrm{HEPES} /$ $\mathrm{MgCl}_{2}$ ( $\mathrm{NaCl}$ buffer) that was used to dilute the sucrose solution immediately prior to sonication. Dialysis was performed for $17 \mathrm{hr}$ at $4^{\circ} \mathrm{C}$ and then for $1 \mathrm{hr}$ at room temperature to remove most of the detergent. When an acetylcholine-generating system was added, the dialysis buffer also contained $200 \mu \mathrm{M}$ CoA and $200 \mu \mathrm{M}$ acetylphosphate. The proteoliposomes were dialyzed against $10^{4}$ vol by using several batches of external buffer. After dialysis, a precipitate was formed that was centrifuged at $4^{\circ} \mathrm{C}(100,000 \times g, 60 \mathrm{~min})$ and surface washed once with ice-cold $0.32 \mathrm{~m}$ sucrose. This pellet was resuspended in a small volume of $0.32 \mathrm{M}$ sucrose and was used for uptake and release experiments immediately, because subsequent freezing and thawing of the preparation gave inconsistent results for high affinity choline uptake.

Choline uptake experiments. Synaptosomal $\left[{ }^{3} \mathrm{H}\right] \mathrm{cho}-$ line uptake was measured by diluting the $0.32 \mathrm{M}$ sucrose suspension 20 -fold with a saline medium (150 mM NaCl, $5 \mathrm{mM} \mathrm{MgCl}_{2}, 5 \mathrm{~mm} \mathrm{HEPES}$, and $5 \mathrm{~m} \mathrm{M} \mathrm{KCl}$ ) plus or minus hemicholinium-3 (HC-3) $(10 \mu \mathrm{M})$. After a 2-min incubation at $20^{\circ} \mathrm{C}$ in this saline medium, $\left[{ }^{3} \mathbf{H}\right]$ choline (New England Nuclear Co., Boston, MA; specific activity $60 \mathrm{Ci} / \mathrm{mmol}$ ) was added to the specified concentration and its uptake terminated 1 min later by rapid vacuum filtration on Millipore filters (type HA, $0.45 \mu$ pore diameter). These filters were immediately washed twice with cold saline medium, dissolved in ethyleneglycol monomethylether, and counted in Formula 963 scintillator. Preliminary experiments revealed that uptake during the first minute was not significantly increased by adding dextrose, $\mathrm{CaCl}_{2}$, or $\mathrm{KCl}$. Proteoliposomal uptake of $\left[{ }^{3} \mathrm{H}\right]$ choline was measured by diluting the sucrose suspension containing proteoliposomes immediately after the high speed centrifugation with the same saline medium used to measure synaptosomal choline uptake, sans $\mathrm{KCl}$, except as otherwise noted. Proteoliposomes were incubated at $20^{\circ} \mathrm{C}$ for $1 \mathrm{~min}$, and then $\left[{ }^{3} \mathrm{H}\right]$ choline was added to the specific concentration. At various times thereafter, samples were diluted 10 -fold with cold saline buffer and centrifuged for $10 \mathrm{~min}$ at $40,000 \times \mathrm{g}$. These pellets were washed twice with ice-cold saline medium and then either (1) counted directly as described above for synaptosomes or (2) assayed for $\left[{ }^{3} \mathrm{H}\right]$ choline and $\left[{ }^{3} \mathrm{H}\right] \mathrm{ACh}$ as described previously (Nemeth and Cooper, 1978).

Release of $\left[{ }^{3} \mathrm{H}\right] \mathrm{ACh}$ and $\left[{ }^{3} \mathrm{H}\right]$ choline. $\left[{ }^{3} \mathrm{H}\right] \mathrm{ACh}$ and $\left[{ }^{3} \mathrm{H}\right]$ choline release was measured from proteoliposomes that were reconstituted in the presence of an ACh-generating system after: (1) pre-incubating them for 2 min at $30^{\circ} \mathrm{C}$ in order to synthesize $\mathrm{AcCoA}$; (2) adding $10 \mu \mathrm{M}$ $\left.{ }^{3} \mathrm{H}\right]$ choline for a 2 -min incubation at $20^{\circ} \mathrm{C}$ in a separate bath (in some samples, choline and $\mathrm{ACh}$ levels were assayed at this stage to determine choline uptake and ACh synthesis); (3) the twice-washed preparation containing $\left[{ }^{3} \mathrm{H}\right]$ choline and newly synthesized $\left[{ }^{3} \mathrm{H}\right] \mathrm{ACh}$ was incubated at $0^{\circ}$ or $20^{\circ}$ in $50 \mu \mathrm{l}$ of either $150 \mathrm{~mm} \mathrm{NaCl}$ or $\mathrm{KCl}$, plus $5 \mathrm{~mm} \mathrm{MgCl}_{2}, 5 \mathrm{~mm}$ HEPES (pH 7.6), and 50 $\mu \mathrm{M}$ eserine; and (4) the release was stopped 1 min later by adding $500 \mu \mathrm{l}$ of the ice-cold saline medium. 'The sample was centrifuged at $40,000 \times g$ for $8 \mathrm{~min}$, and the supernatant and pellet were assayed for labeled $\mathrm{ACh}$ and choline. The temperature-dependent release of each compound was calculated and expressed as a percentage of the original level.

In a related experiment, the calcium dependencies of $\left[{ }^{3} \mathrm{H}\right] \mathrm{ACh}$ (Amersham, London; specific activity $200 \mathrm{mCi}$ / mmol) and $\left[{ }^{3} \mathrm{H}\right]$ choline uptake were studied to ascertain whether some plasma membrane fragments had been inverted, allowing for reverse calcium-dependent release (i.e., uptake) of either compound. Because the purpose of this experiment was to study inverted proteoliposomal activity, they were preloaded with a NaCl-containing buffer, instead of the $\mathrm{KCl}$ buffer, and exposed to an external $\mathrm{KCl}$ buffer instead of the normal saline buffer. Furthermore, because the concentration of ACh in the cholinergic terminal is estimated in the millimolar range, and because we wanted to reproduce this situation when studying reverse release of the transmitter, we used a 1 mM concentration of $\left[{ }^{3} \mathrm{H}\right] \mathrm{ACh}$ (or labeled choline for control) for the uptake. The uptake incubation was terminated after 1 min at $20^{\circ} \mathrm{C}$, plus or minus $1 \mathrm{mM} \mathrm{CaCl}_{2}$.

In some experiments, proteoliposomes containing the ACh-generating system were incubated under identical conditions bul wilhout labeled choline to determine the AcCoA and choline acetyltransferase levels. AcCoA levels were assayed by a modification of the procedure of Ricny and Tucek (1981). A 20- $\mu$ l aliquot of the saline medium suspension was diluted in $250 \mu \mathrm{l}$ of prewarmed $\left(37^{\circ} \mathrm{C}\right) 10 \mathrm{~mm} \mathrm{NaH} \mathrm{PO}_{4}, \mathrm{pH} 8$, containing $100 \mu \mathrm{M}$ $\left[{ }^{3} \mathrm{H}\right]$ choline $(2 \mathrm{Ci} / \mathrm{mmol}), 10 \mu \mathrm{M}$ eserine sulfate, and 0.025 units of choline acetyltransferase for $10 \mathrm{~min}$. Preliminary experiments indicated that phosphotransacetylase activity (and new AcCoA synthesis) were blocked in the presence of $\mathrm{Na}^{+}$ions, as has been shown previously (Stadtman, 1952). The $\left[{ }^{3} \mathrm{H}\right] \mathrm{ACh}$ and unreacted $\left[{ }^{3} \mathrm{H}\right] \mathrm{cho}-$ line were extracted in $1 \mathrm{ml}$ of butyronitrile containing 10 $\mathrm{mg} / \mathrm{ml}$ of sodium tetraphenylboron and were then separated in two sequential steps: first, with choline kinase phosphorylation and then with high voltage electrophoresis (Sen et al., 1976). Several concentrations of AcCoA $(0.5,2$, and $5 \mu \mathrm{M})$ were added to some samples as internal standards. Choline acetyltransferase activity was assayed as described previously (Meyer et al., 1981). 
Electron microscopy. Electron microscopy of plasma membrane ghosts or proteoliposomes was performed as described previously (Sen et al., 1976).

Protein determinations. Protein levels were estimated by the Bio-Rad procedure (Bradford, 1976).

\section{Results}

Proteoliposomal cholinergic activity. The phosphatidylcholine-proteoliposome preparation consisted of uniformly sized vesicles, 200 to $400 \mathrm{~A}$ in diameter (Fig. 1). Choline uptake was reduced in the absence of tissue, with lower phosphatidylcholine concentrations, or with different sonication regimens (Table I). Interestingly, the basal proteoliposomal $\left[{ }^{3} \mathrm{H}\right]$ choline uptake was higher than that of synaptosomes when expressed per milligram of protein. The hemicholinium-3-sensitive component of the proteoliposomal $\left[{ }^{3} \mathrm{H}\right]$ choline uptake was maximal with a phosphatidylcholine concentration of about 1 to $2 \mathrm{mg} /$ $\mathrm{ml}$; higher concentrations of this lipid increased low affinity choline (i.e., HC-3 insensitive) uptake dramatically without increasing the high affinity component (Table I). HC-3-sensitive choline uptake was nonexistent in the absence of tissue, and this high affinity transport

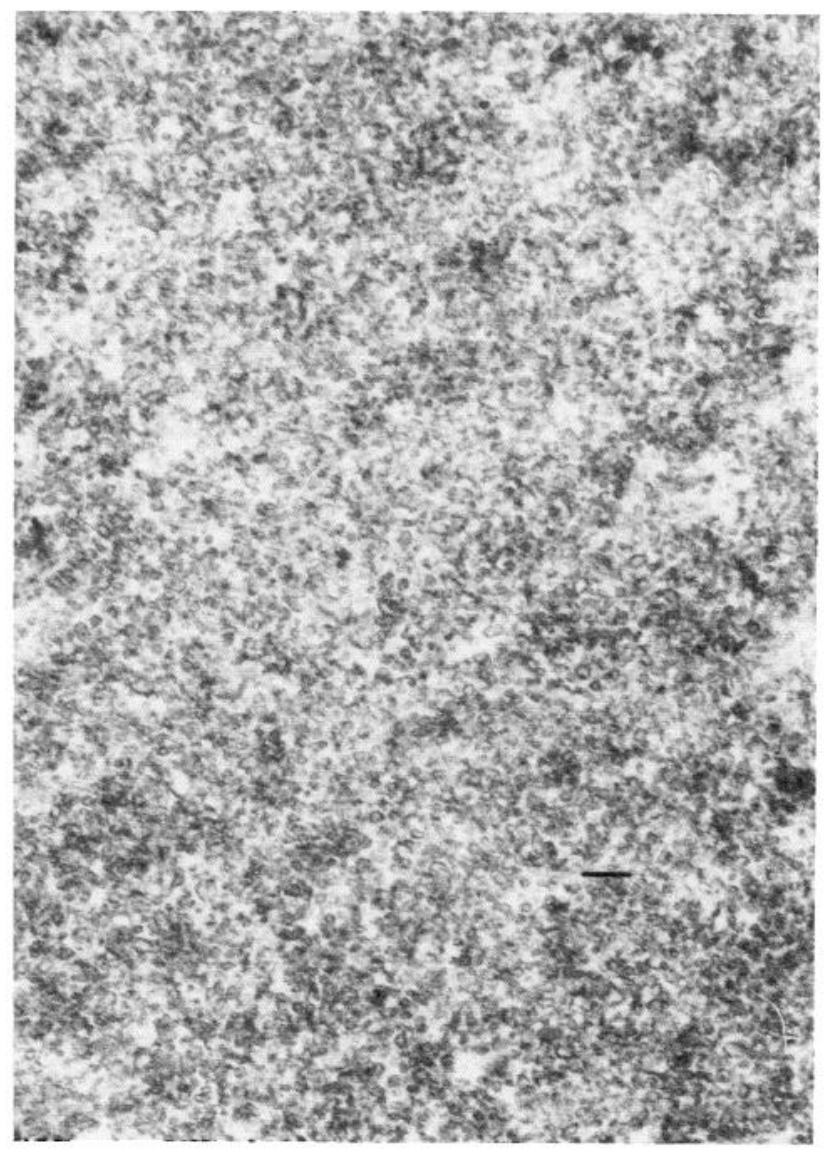

Figure 1. Electron micrograph of proteoliposomes enlarged 33,000 . Proteoliposomes were prepared from rat cortical synaptic plasma membranes with an internal milieu of $150 \mathrm{~mm}$ $\mathrm{KCl}, 5 \mathrm{mM} \mathrm{MgCl}_{2}$, and $5 \mathrm{~mm}$ HEPES (pH 7.6), and they were then resuspended in a medium of $150 \mathrm{~mm} \mathrm{NaCl}, 5 \mathrm{~mm} \mathrm{MgCl}_{2}$, and $5 \mathrm{~mm}$ HEPES (pH 7.6). This suspension was fixed, stained, and magnified as shown here (the horizontal line corresponds to $1500 \mathrm{~A}$ ).
TABLE I

Factors affecting proteoliposomal $\left[{ }^{\beta} \mathrm{H}\right]$ choline uptake

\begin{tabular}{|c|c|c|c|c|}
\hline \multirow{3}{*}{ Sonication Regimen ${ }^{b}$} & \multicolumn{4}{|c|}{$\left[{ }^{3} \mathrm{H}\right]$ Choline Uptake ${ }^{\alpha}$} \\
\hline & \multicolumn{2}{|c|}{ +Tissue } & \multicolumn{2}{|c|}{-Tissue } \\
\hline & Normal & HC-3 & Normal & HC-3 \\
\hline & \multicolumn{4}{|c|}{$\mathrm{pmol} / 50 \mathrm{ml} / \mathrm{min}$} \\
\hline \multicolumn{5}{|l|}{$\begin{array}{l}\text { Phosphatidylcholine } \\
\text { concentration }\end{array}$} \\
\hline $0 \mathrm{mg} / \mathrm{ml}$ & $10.2 \pm 1.3$ & $6.8 \pm 0.9$ & & \\
\hline $0.3 \mathrm{mg} / \mathrm{ml}$ & $9.3 \pm 2.1$ & $8.3 \pm 0.8$ & $2.4 \pm 1.1$ & $1.4 \pm 0.6$ \\
\hline $1.0 \mathrm{mg} / \mathrm{ml}$ & $21.4 \pm 3.2$ & $11.9 \pm 1.7$ & $3.5 \pm 0.4$ & $4.2 \pm 1.5$ \\
\hline $2.0 \mathrm{mg} / \mathrm{ml}$ & $19.9 \pm 1.2$ & $10.7 \pm 0.8$ & $4.4 \pm 0.5$ & $6.9 \pm 2.0$ \\
\hline $5.0 \mathrm{mg} / \mathrm{ml}$ & $21.5 \pm 0.9$ & $13.6 \pm 0.7$ & $7.3 \pm 0.9$ & $11.1 \pm 2.3$ \\
\hline $10.0 \mathrm{mg} / \mathrm{ml}$ & $32.8 \pm 3.7$ & $29.5 \pm 1.8$ & $19.4 \pm 2.1$ & $26.1 \pm 4.8$ \\
\hline \multicolumn{5}{|l|}{ Sonication duration } \\
\hline $0 \mathrm{sec}$ & $14.8 \pm 3.7$ & $9.7 \pm 1.4$ & & \\
\hline $15 \mathrm{sec}$ & $20.1 \pm 1.9$ & $10.2 \pm 1.0$ & & \\
\hline $30 \mathrm{sec}$ & $23.9 \pm 2.7$ & $11.7 \pm 1.2$ & & \\
\hline $60 \mathrm{sec}$ & $16.4 \pm 3.2$ & $9.8 \pm 1.3$ & & \\
\hline $120 \mathrm{sec}$ & $8.3 \pm 3.1$ & $6.3 \pm 2.8$ & & \\
\hline
\end{tabular}

${ }^{a}$ Liposomes were prepared in $\mathrm{KCl}$ medium plus or minus rat cortical synaptic plasma membranes as described in Figure 1. $\left[{ }^{3} \mathrm{H}\right]$ Choline $(1$ $\mu \mathrm{M})$ uptake was then measured for $30 \mathrm{sec}$ as described in Figure 2, except that $10 \mu \mathrm{M}$ hemicholinium-3 was added to some samples. Values are means \pm SEM of five samples and are expressed per $50 \mathrm{ml}$ of final incubation suspension containing identically treated liposomes or proteoliposomes. Because the proteoliposomal protein concentration in this suspension was 0.019 to $0.022 \mathrm{mg} / \mathrm{ml}$, these uptake values are comparable to those in other diagrams.

${ }^{b}$ Two sonication conditions were varied: the standard $2 \mathrm{mg} / \mathrm{ml}$ of phosphatidylcholine concentration or the 30 -sec sonication duration.

inhibitor actually increased $\left[{ }^{3} \mathrm{H}\right]$ choline uptake in the presence of $10 \mathrm{mg} / \mathrm{ml}$ of phosphatidylcholine alone.

The time course and temperature dependencies of proteoliposomal $\left[{ }^{3} \mathrm{H}\right]$ choline uptake in control or $\mathrm{HC}-3$ treated preparations are shown in Figure 2. The initial $\left[{ }^{3} \mathrm{H}\right]$ choline uptake increased with ambient temperature, but similar choline levels were attained at $20^{\circ}$ and $37^{\circ} \mathrm{C}$ by $0.5 \mathrm{~min}$ in controls. Overshoots were observed at both of these temperatures, but they varied from day to day with regard to onset, duration, and magnitude and are, therefore, masked to some extent in Figure 2, which summarizes data from several different experiments (see Fig. 4, below). HC-3 transiently reduced $\left[{ }^{3} \mathrm{H}\right]$ choline uptake, but at the highest temperature it elevated $\left[{ }^{3} \mathrm{H}\right]$ choline levels several minutes later compared to controls. This may reflect some stabilizing action on membranes or an inhibition of $\left[{ }^{3} \mathrm{H}\right]$ choline efflux. Because the hemicholinium-3-sensitive component of $\left[{ }^{3} \mathrm{H}\right]$ choline uptake was most protracted at $20^{\circ} \mathrm{C}$, this temperature was used to study hemicholinium-3-sensitive proteoliposomal ACh synthesis below. Hemicholinium-3induced inhibition of $\left[{ }^{3} \mathrm{H}\right]$ choline uptake was attenuated at a higher choline concentration $(100 \mu \mathrm{M})$, but sodiumdependent uptake was not, in proteoliposomes and synaptosomes, indicating that hemicholinium-3 was a competitive inhibitor in both preparations (Fig. 3). In order to determine whether membrane potential or an ion gradient was important for sodium-dependent choline uptake, some proteoliposomes were prepared with sodium ions internally instead of potassium ions, and they 


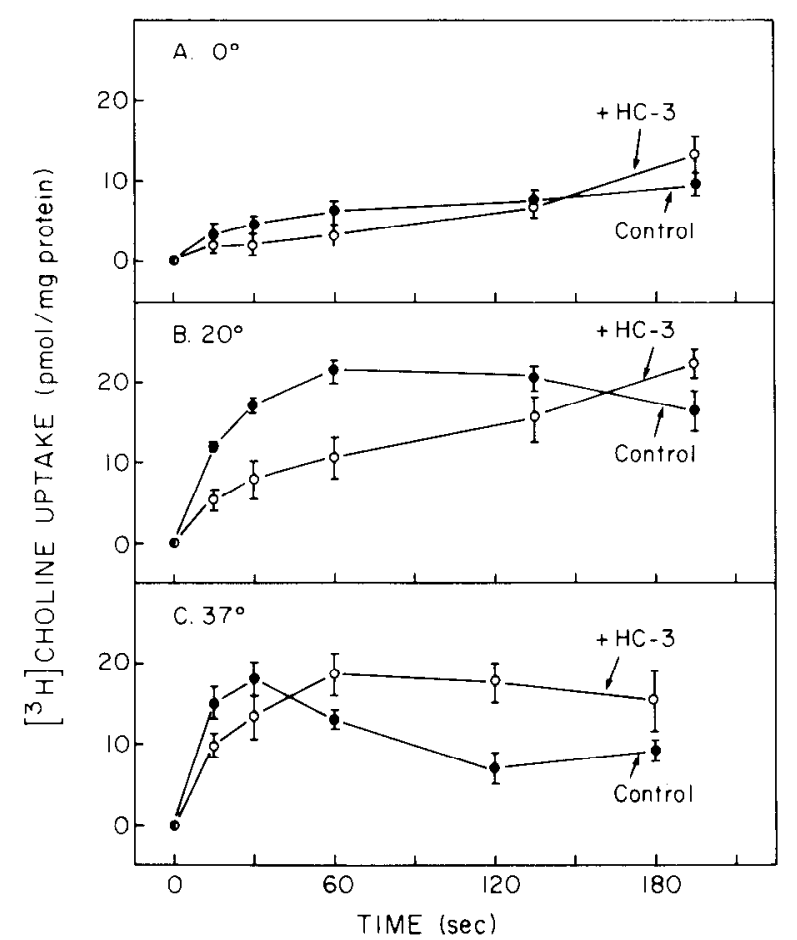

Figure 2. Effects of time and temperature on proteoliposomal $\left[{ }^{3} \mathrm{H}\right]$ choline uptake. Proteoliposomes, prepared as in Figure 1, were pre-incubated for $1 \mathrm{~min}$ in the saline medium described in Figure 1 and at the specified temperature plus or minus hemicholinium-3. $\left[{ }^{3} \mathrm{H}\right]$ Choline ( $1 \mathrm{mM}$, final specific activity of $20 \mathrm{Ci} /$ mmol) was then added and its uptake terminated at specified times by diluting the sample 10 -fold with cold saline medium and then centrifuging it for $10 \mathrm{~min}$ at $40,000 \times \mathrm{g}$. After two surface washes, proteoliposomal $\left[{ }^{3} \mathrm{H}\right]$ choline uptake was measured in a scintillation counter. All values are expressed as means \pm SEM of four to five samples.

were then incubated with $1 \mu \mathrm{M}\left[{ }^{3} \mathrm{H}\right]$ choline for various times (Fig. 4). Initial $\left[{ }^{3} \mathrm{H}\right]$ choline uptake was significantly slower in the sodium-loaded proteoliposomes, but it eventually reached similar plateaus in both groups. This particular experiment, which was conducted with one batch of samples, demonstrates a typical overshoot in choline uptake in the control groups but not in the samples in which there is no artificially imposed membrane potential. Finally, proteoliposomal choline uptake was inhibited by external potassium ions, with nearly maximal inhibition observed at only $20 \mathrm{~mm} \mathrm{KCl} \mathrm{(Fig.} \mathrm{5).}$

Proteoliposomal $\left[{ }^{3} \mathrm{H}\right] \mathrm{ACh}$ synthesis and release. In proteoliposomes containing $\mathrm{KCl}$ buffer internally along with the ACh-generating system, about $10 \%$ of the $\left[{ }^{3} \mathrm{H}\right]$ choline taken up was subsequently recovered at $\left[{ }^{3} \mathrm{H}\right] \mathrm{ACh}$, regardless of the external medium (Table II). $\left[{ }^{3} \mathrm{H}\right]$ Choline uptake and $\left[{ }^{3} \mathrm{H}\right] \mathrm{ACh}$ synthesis were both reduced by $10 \mu \mathrm{M}$ hemicholinium-3 and more dramatically by $\mathrm{NaCl}$ replacement with KCl externally. Similarly prepared and incubated proteoliposomes contained between 800 and $1200 \mathrm{pmol} / \mathrm{mg}$ of protein of AcCoA and 0.02 to $0.03 \mathrm{unit} / \mathrm{mg}$ of protein of choline acetyltransferase.

Newly synthesized proteoliposomal $\left[{ }^{3} \mathrm{H}\right] \mathrm{ACh}$ was released in a calcium-dependent manner by a depolarizing KCl buffer (Fig. 6), whereas $\left[{ }^{3} \mathrm{H}\right]$ choline efflux was not changed. Interestingly, the absolute rate of $\left[{ }^{3} \mathrm{H}\right] \mathrm{ACh}$ release was lower from the preparation preloaded with $\left[{ }^{3} \mathrm{H}\right]$ choline when high affinity uptake was blocked with hemicholinium-3 (Fig. 6, upper right panel) (han that from untreated proteoliposomes (Fig. 6, upper left panel), although hemicholinium-3 had no direct effect on $\left[{ }^{3} \mathrm{H}\right] \mathrm{ACh}$ release (not shown).

The uptake of $\left[{ }^{3} \mathrm{H}\right] \mathrm{ACh}$ but not of $\left[{ }^{3} \mathrm{H}\right]$ choline was elevated by calcium ions in the proteoliposome preparation (Table III). This temperature-dependent uptake was not blocked by hemicholinium-3.

\section{Discussion}

As noted in the introduction, the mechanism of neurotransmitter release remains one of the unsolved and controversial problems in neurobiology, with most neurochemical evidence arguing against an exocytotic mechanism. The goal of the present research was to determine if this release process could be demonstrated in neuronal membrane preparations that were devoid of synaptic vesicles. In preliminary experiments, synaptic plasma membrane ghosts were prepared from cerebral cortices and loaded osmotically with either labeled ACh or choline. These ghosts released $\mathrm{ACh}$ but not choline in a calcium-dependent manner in the presence of veratridine or potassium depolarization; however, only a small frac-

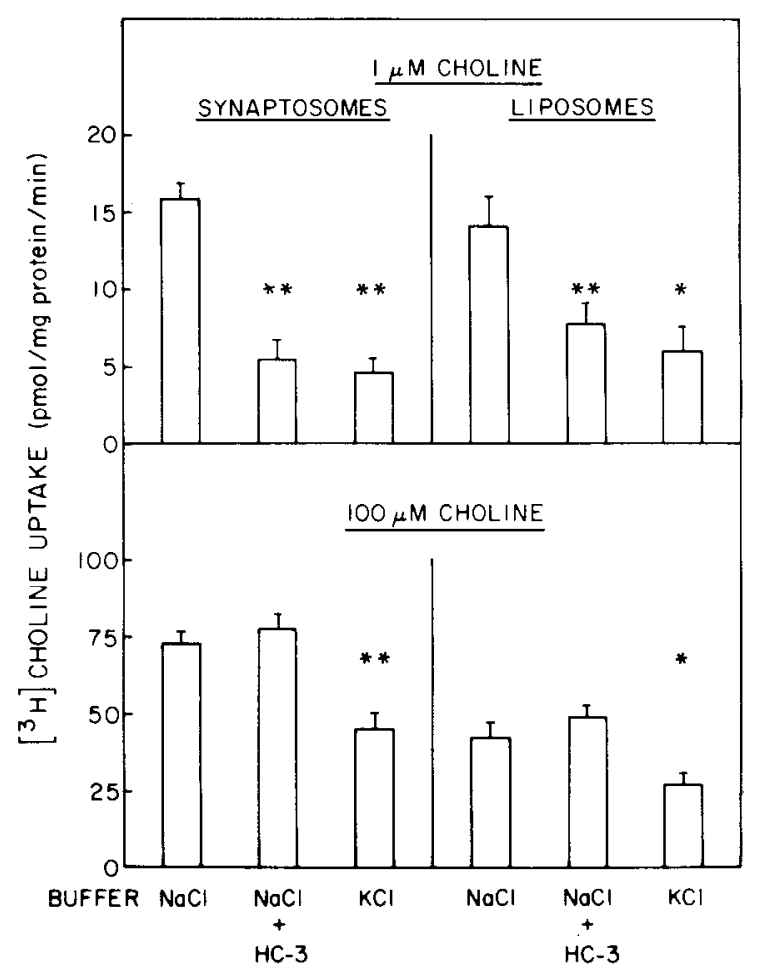

Figure 3. Concentration-dependent inhibition of $\left[{ }^{3} \mathrm{H}\right]$ choline uptake by $\mathrm{HC}-3$ and external $\mathrm{KCl}$. Rat cortical synaptosomes or their derived proteoliposomes, prepared as in Figure 1, were pre-incubated for $1 \mathrm{~min}$ at $20^{\circ}$ in external saline medium, saline medium plus $10 \mu \mathrm{M} \mathrm{HC}-3$, or $\mathrm{KCl}$ medium. $\left[{ }^{3} \mathrm{H}\right] \mathrm{Choline}(1$ or $100 \mu \mathrm{M})$; final specific activity of 10 or $0.1 \mathrm{Ci} / \mathrm{mmol}$, respectively) was then added, and its uptake was measured after $0.5 \mathrm{~min}$ as described in Figure 2. Values are expressed as means \pm SEM of three to five samples. $* *, p<0.01 ; *, p<0.05$, compared to control, saline medium external group. 


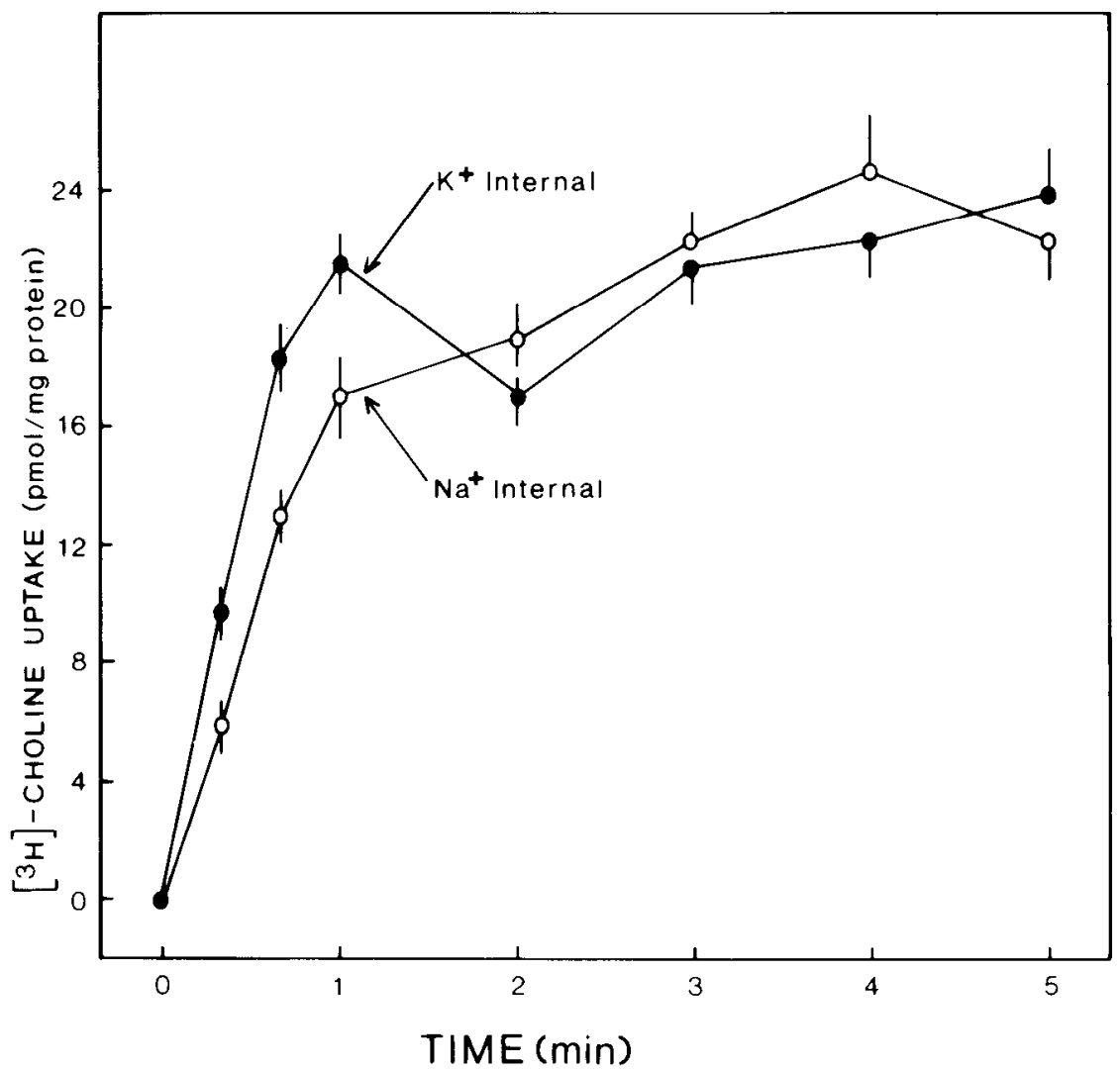

Figure 4. Effects of preloading proteoliposomes with saline medium on $\left[{ }^{3} \mathrm{H}\right]$ choline uptake. Proteoliposomes were prepared as described in Figure 1, except that internal $\mathrm{NaCl}$ iso-osmotically replaced $\mathrm{KCl}$ in some samples. $\left[{ }^{3} \mathrm{H}\right]$ Choline uptake was measured as in Figure 2, at $20^{\circ} \mathrm{C}$ for various periods and was expressed as mean \pm SEM of four samples.

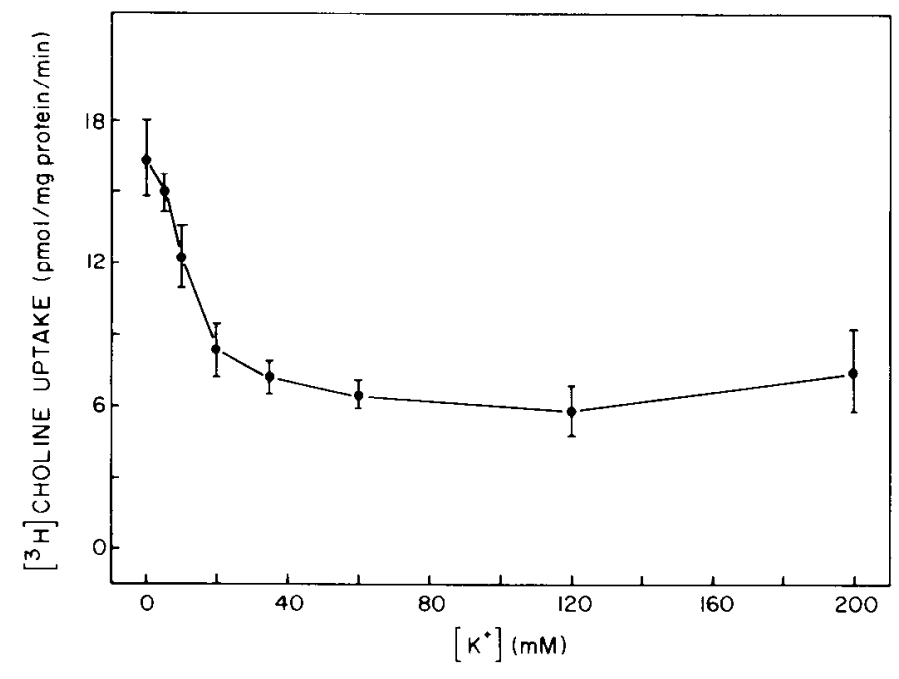

Figure 5. Effects of external $\mathrm{KCl}$ on proteoliposomal $\left[{ }^{3} \mathrm{H}\right]$ choline uptake. Proteoliposomes were prepared as described in Figure 1, then were pre-incubated for $1 \mathrm{~min}$, incubated with $\left[{ }^{3} \mathrm{H}\right]$ choline at $20^{\circ} \mathrm{C}$ for $0.5 \mathrm{~min}$, washed twice, and assayed for $\left[{ }^{3} \mathrm{H}\right]$ choline as described in Figure 2. In some samples, the $\mathrm{NaCl}$ in external medium (pre-incubation and incubation) was replaced iso-osmotically with increasing concentrations of $\mathrm{KCl}$. [ $\left.{ }^{3} \mathrm{H}\right] \mathrm{Choline}$ uptake is presented as the mean \pm SEM of three samples.
TABLE II

Proteoliposomal uptake of $\left[{ }^{3} \mathrm{H}\right]$ choline and synthesis of $\left[{ }^{3} \mathrm{H}\right] \mathrm{ACh}$

\begin{tabular}{|c|c|c|}
\hline \multirow{2}{*}{ External Medium } & \multicolumn{2}{|c|}{ Proteoliposomal Levels ${ }^{a}$} \\
\hline & $\left.\Gamma^{3} \mathrm{H}\right\rceil$ Choline & {$\left[{ }^{3} \mathrm{H}\right] \mathrm{ACh}$} \\
\hline & \multicolumn{2}{|c|}{ pmol/mg of protein } \\
\hline $\mathrm{NaCl}$ & $126.4 \pm 10.3$ & $12.8 \pm 2.3$ \\
\hline $\mathrm{NaCl}+10 \mu \mathrm{M} \mathrm{HC}-3$ & $91.0 \pm 12.2$ & $4.5 \pm 0.9$ \\
\hline $\mathrm{KCl}$ & $56.2 \pm 3.6$ & $1.4 \pm 0.6$ \\
\hline
\end{tabular}

"Proteoliposomes containing an ACh-generating system were prepared and incubated with $10 \mu \mathbf{M}\left[{ }^{3} \mathrm{H}\right]$ choline as in Figure 6. After stopping the uptake with cold saline medium and centrifugation, samples were lysed, and their total $\left[{ }^{3} \mathrm{H}\right]$ choline and $\left[{ }^{3} \mathrm{H}\right] \mathrm{ACh}$ levels were assayed and expressed as means \pm SEM of five samples.

tion of the total $\mathrm{ACh}$ was releasable from this neurochemically heterogeneous preparation. In order to look at release from a higher percentage of cholinergic plasma membrane ghosts, we attempted to preferentially load these ghosts with ACh via the high affinity choline transporter, which is unique to cholinergic terminals (Murrin, 1980), after supplementation with an ACh-generating system. Because hypo-osmotically prepared ghosts lost this choline transport activity, the present iso-osmotic lysis procedure was developed to reconstitute this activity into proteoliposomes. That these proteoliposomes 


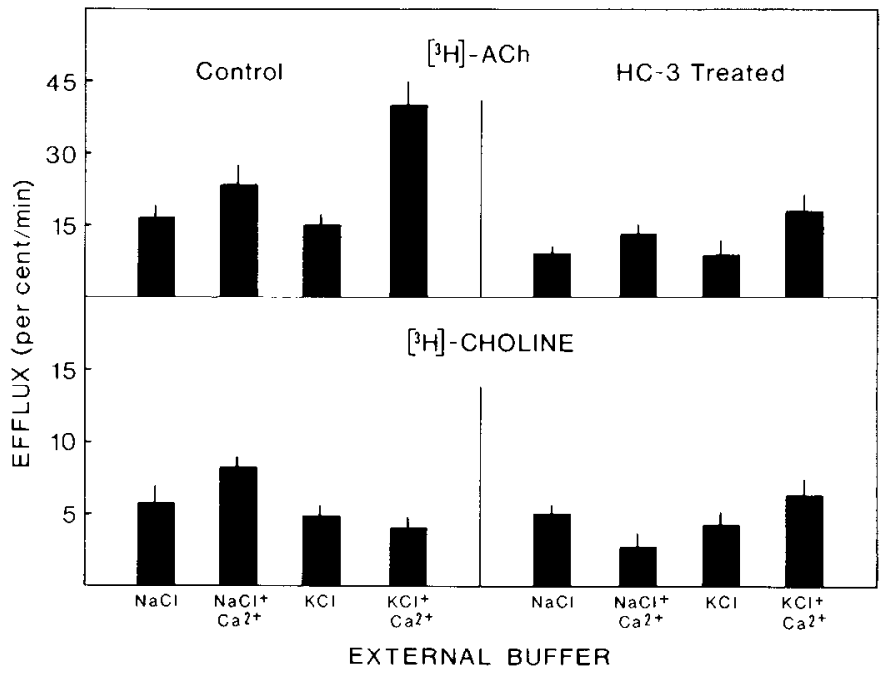

Figure 6. Efflux of $\left[{ }^{3} \mathrm{H}\right]$ choline and newly synthesized $\left[{ }^{3} \mathrm{H}\right] \mathrm{ACh}$ from proteoliposomes. Proteoliposomes were prepared as in Figure 1 but were supplemented with $200 \mu \mathrm{M}$ acetylphosphate, $200 \mu \mathrm{M} \mathrm{CoA}, 10 \mu \mathrm{g} / \mathrm{ml}$ of phosphotransacetylase, and $0.2 \mathrm{mg} / \mathrm{ml}$ of choline acetyltransferase. Following a 2min pre-incubation at $30^{\circ} \mathrm{C}$ in saline medium $\pm 10 \mu \mathrm{M} \mathrm{HC}-3$, tubes were transferred to a $20^{\circ} \mathrm{C}$ bath and then $10 \mu \mathrm{M}$ $\left[{ }^{3} \mathrm{H}\right]$ choline was added. One minute later, uptake was terminated as described in Figure 2. Following centrifugation, proteoliposomes were resuspended in $\mathrm{NaCl}$ or $\mathrm{KCl}$ medium \pm 1 $\mathrm{mM} \mathrm{Ca}{ }^{2+}$ at $0^{\circ} \mathrm{C}$ for $1 \mathrm{~min}$, and the temperature-dependent efflux of $\left[{ }^{3} \mathrm{II}\right]$ choline and $\left[{ }^{3} \mathrm{H}\right] \mathrm{ACh}$ was measured radioenzymatically after centrifugation. Values were expressed as means $\pm \operatorname{SEM}(N=5 /$ group) of the percent of the total proteoliposomal levels of $\left[{ }^{3} \mathrm{H}\right]$ choline or $\left[{ }^{3} \mathrm{H}\right] \mathrm{ACh}$ prior to release (described in Table III).

TABLE III

Effects of calcium ions on the proteoliposomal uptake of $\left[{ }^{3} \mathrm{H}\right] \mathrm{ACh}$ and $\left[^{3} \mathrm{H}\right]$ choline

\begin{tabular}{lcr}
\hline \multirow{2}{*}{ External Medium } & \multicolumn{2}{c}{ Uptake $^{a}$} \\
\cline { 2 - 3 } & {$\left[{ }^{3} \mathrm{H}\right]$ Choline } & {$\left[{ }^{3} \mathrm{H}\right] \mathrm{ACh}$} \\
\hline & & nmol/mg of protein $/$ min \\
$\mathrm{Ca}^{2+}$ free & & \\
$25^{\circ} \mathrm{C}$ & $13.2 \pm 0.6$ & $9.7 \pm 1.0$ \\
$0^{\circ} \mathrm{C}$ & $7.7 \pm 1.4$ & $4.9 \pm 0.8$ \\
$1 \mathrm{mM} \mathrm{Ca}^{2+}$ & & \\
$25^{\circ} \mathrm{C}$ & $15.1 \pm 2.1$ & $17.3 \pm 1.3$ \\
$0^{\circ} \mathrm{C}$ & $7.1 \pm 0.9$ & $6.8 \pm 0.5$ \\
\hline
\end{tabular}

${ }^{a}$ Proteoliposomes containing saline medium internally were incubated in $\mathrm{KCl}$ medium $\pm 1 \mathrm{~mm} \mathrm{Ca}{ }^{2+}$ and either $1 \mathrm{~mm}\left[{ }^{3} \mathrm{H}\right]$ choline or 1 $\mathrm{mM}\left[{ }^{3} \mathrm{H}\right] \mathrm{ACh}$. Uptake was measured as in Figure 2 and was expressed as means \pm SEM of four samples.

retained functional high and low affinity choline transport was demonstrated kinetically and pharmacologically in a previous paper (Meyer and Cooper, 1982). The purpose of this paper was to demonstrate a variety of limitations associated with this preparation, as well as to show that it could be used in conjunction with an AChgenerating system to synthesize this transmitter and release it from cholinergically derived proteoliposomes in particular.

The synaptosomal high affinity choline transporter $\left(K_{m} 1\right.$ to $\left.2 \mu \mathrm{M}\right)$ and low affinity uptake process $\left(K_{m} 60\right.$ to
$80 \mu \mathrm{M})$ have been studied extensively with respect to their external ionic dependencies and pharmacological sensitivities. The synaptosomal high affinity transporter is believed to regulate ACh synthesis under conditions that stimulate release (Hasa and Noda, 1973; Simon et al., 1976; Meyer et al., 1982b), whereas low affinity choline uptake presumably subserves phospholipid synthesis. Inasmuch as neither choline acetyltransferase nor choline kinase activity was recovered with the proteoliposomes (data not shown), a phvsical coupling with the choline transporter, if indeed present, can be dissociated by this detergent treatment.

$\left[{ }^{3} \mathrm{H}\right]$ Choline uptake was inhibited by potassium ions in proteoliposomes, as has been demonstrated in brain synaptosomes (Meyer et al., 1982b); however, we were unable to stimulate $\left[{ }^{3} \mathrm{H}\right]$ choline uptake by prior potassium depolarization, a phenomenon that has been demonstrated in several neuronal preparations (Murrin and Kuhar, 1976; Grewaal and Quastel, 1973). This difference supports the suggestion that the presence of endogenous ACh or some other intracellular constituents absent in the reconstituted system may play a role in regulating choline uptake. Experiments are in progress to elucidate this potential regulatory factor, which should be useful in eventually modulating cholinergic synthesis and turnover.

That proteoliposomal choline accumulation depends on either a sodium gradient or a membrane potential is suggested by the following observations: (1) choline is concentrated about 4 -fold by liposomes against an external $1 \mu \mathrm{M}$ concentration (Meyer and Cooper, 1982), and this probably underestimates the accumulation in cholinergically derived liposomes; (2) there is no energy source for choline accumulation except the membrane potential or binding to intraproteoliposomal sites; (3) gramacidin$D$, which promotes $\mathrm{K}^{+}-\mathrm{Na}^{+}$exchange (Eisenman et al., 1980), inhibits choline uptake; and (4) loading proteoliposomes internally with sodium ions reduces choline accumulation. Whether other intracellular constituents (ACh, calcium, magnesium) affect high affinity choline uptake requires further study.

Several apparent differences between high affinity choline uptake in synaptosomes versus proteoliposomes should be discussed. First, the time course and duration of high affinity choline transport are more rapid in the proteoliposomes, which is probably due to their much smaller volume. Second, hemicholinium-3 seems to be a less potent inhibitor of choline uptake in the proteoliposomes than in synaptosomes in which its $K_{i}$ is less than $1 \mu \mathrm{M}$. Whether this reflects an alteration in the transport system during reconstitution or some other process, such as the inhibition of $\left[{ }^{3} \mathrm{H}\right]$ choline efflux by this drug from normal or inverted proteoliposomes, is not clear. It should be noted that the rapid equilibration of $\left[{ }^{3} \mathrm{H}\right] \mathrm{cho}-$ line uptake in proteoliposomes makes quantitative comparisons between this preparation and synaptosomes difficult. Finally, it should be noted that synaptosomal high affinity choline uptake is dependent on potassium ions for optimal activity (Yamamura and Snyder, 1972), whereas proteoliposomes are apparently not. However, whether potassium ions are directly involved in synaptosomal choline transport is unclear, because (1) potas- 
sium-free external media probahly inhibit $\mathrm{Na}^{+}, \mathrm{K}^{+}$-ATPase, thereby depolarizing the nerve terminal and inhibiting choline transport indirectly; and (2) we see no immediate potentiation by potassium ions on high affinity choline uptake in synaptosomes, as noted under "Materials and Methods." Indeed, the optimal potassium concentration for high affinity choline transport is about $5 \mathrm{mM}$, which is consistent with a potential $\mathrm{Na}^{+}, \mathrm{K}^{+}-\mathrm{ATP}$ ase stimulatory role for the ion. We do not know the concentration of potassium ions along the proteoliposomal plasma membrane even in presumably potassiumfree media either, because these reconstituted vesicles may rapidly release their potassium into the surrounding medium.

When properly supplemented, proteoliposomes were able to synthesize ACh de novo from choline taken up by either the high or low affinity uptake process. Specificity derived from using a low enough concentration of choline to be taken up preferentially by the high affinity transporter. Because deoxycholate does not completely solubilize membranes but disintegrates them into small fragments that do not sediment at $100,000 \times g$ for several hours at least, the high affinity choline transporter and ACh release channel might be reconstituted together in proteoliposomes. That this is the case is suggested by the observation that a higher percentage of $\mathrm{ACh}$ was released from proteoliposomes loaded with choline under normal conditions than in the presence of hemicholinium-3, although this drug had no direct effect on ACh release. The specificity of this release process was demonstrated by the fact that choline was not released in a calciumdependent manner. That some of the $\mathrm{ACh}$ release "channels" were reconstituted in an inverted form is suggested by the calcium-dependent uptake of $\mathrm{ACh}$, but not choline, into the proteoliposomes. Because we were attempting to study inverted vesicles, the $\mathrm{NaCl} / \mathrm{KCl}$ ratios were also inverted internally/externally. Millimolar ACh concentrations were used in this experiment because we were not studying a choline transporter moiety but a potential ACh membrane pore that probably normally is exposed to millimolar intracellular ACh concentrations. This calcium-dependent uptake is probably not due to any bidirectionality of the ACh pore, because calcium-dependent ACh uptake is not observed in intact nerve terminals. Inversion of transport activity has been observed following similar reconstitution procedures (Goldin, 1977; Goldin and Rhoden, 1978); however, we presently have no direct measurement of the population of inverted transport moieties (for choline or $\mathrm{ACh}$ ) in our preparation. Calcium-dependent $\mathrm{ACh}$ uptake may offer an alternative and technically easier method for studying release.

Recently, Israel et al. (1981) reported that synaptosomal plasma membrane ghosts from the cholinergic Torpedo electroplax also released ACh but not choline in a calcium-dependent manner, using the calcium ionophore A23187. Another synaptic vesicle-free preparation that releases $\mathrm{ACh}$ in a calcium-dependent manner is the parasympathetic avian ciliary ganglia cell somata (Johnson and Pilar, 1980). It should be noted that none of these release processes are necessarily quantal, nor have other mechanisms of $\mathrm{ACh}$ release been ruled out from the available data. However, taken together, these observations indicate that at least some neuronal $\mathrm{ACh}$ is released via a nonvesicular process.

In summary, we have prepared proteoliposomes from synaptosomal plasma membranes which retain high affinity choline transport as described previously and can be used to synthesize labeled ACh, and this ACh can be released in a calcium-dependent manner. This preparation is directly accessible to manipulations of the internal milieu and should be useful for investigating the membrane events underlying and modulating these cholinergic fluxes.

\section{References}

Bradford, M. (1976) A new technique for the determination of protein in small samples. Anal. Biochem. 72: 248-254.

Cooper, J. R., F. E. Bloom, and R. H. Roth (1982) in The Biochemical Basis of Neuropharmacology, Ed. 4, pp. 91-95, Oxford University Press, London.

Eisenman, G., B. Enos, J. Hagglund, and J. Sandblom (1980) Gramacidin as an example of a single filling ionic channel. Ann. N. Y. Acad. Sci. 339: 8-20.

Goldin, S. M. (1977) Active transport of sodium and potassium ions by the sodium and potassium ion-activated adenosine triphosphatase from renal medulla. Reconstitution of the purified enzyme into a well defined in vitro transport system. J. Biol. Chem. 252: 5630-5642.

Goldin, S. M., and V. Rhoden (1978) Reconstitution and transport specificity fractionation of the human erythrocyte glucose transport system. A new approach for identification and isolation of membrane transport proteins. J. Biol. Chem. 253: 2575-2583.

Grewaal, D. S., and J. H. Quastel (1973) Control of synthesis and release of radioactive acetylcholine in brain slices from the rat. Biochem. J. 132: 1-14.

Haga, T., and H. Noda (1973) Choline uptake systems in rat brain synaptosomes. Biochim. Biophys. Acta 291: 564-575.

Israel, M., Y. Dunant, and R. Manaranche (1979) The present status of the vesicular hypothesis. Prog. Neurobiol. 13: 237275.

Israel, M., B. Lesbats, and R. Manaranche (1981) ACh-release from osmotically shocked synaptosomes refilled with transmitter. Nature 294: 474-475.

Johnson, D. A., and G. Pilar (1980) The release of acetylcholine from post-ganglionic cell bodies in response to depolarization. J. Physiol. (Lond.) 299: 605-619.

Meyer, E. M., and J. R. Cooper (1982) High affinity choline transport in proteoliposomes derived from rat cortical synaptosomes. Science 217: 843-845.

Meyer, F. M., D. I. White, S. B. Andrews, R. J. Barrnett, and J. R. Cooper (1981) Synthesis and radioenzymatic assay of an antimony analog of choline. Biochem. Pharmacol. 30: 3003-3005.

Meyer, E. M., R. J. Barrnett, and J. R. Cooper (1982a) Neurochemical characterization of an antimony-choline analog in rat cortical synaptosomes. J. Neurochem. 39: 321-326.

Meyer, E. M., D. A. Engel, and J. R. Cooper (1982b) Acetylation and phosphorylation of choline following high or low affinity uptake by rat cortical synaptosomes. Neurochem. Res. 7: 749-759.

Murrin, L. C. (1980) High affinity transport of choline in neuronal tissue. Pharmacology 21: 132-140.

Murrin, L. C., and M. J. Kuhar (1976) Activation of high affinity choline uptake in vitro by depolarizing conditions. Mol. Pharmacol. 12: 1082-1090.

Nemeth, E. F., and J. R. Cooper (1978) Effect of somatostatin 
on acetylcholine release from rat hippocampal synaptosomes. Brain Res. 165: 166-170.

Ricny, J., and S. Tucek (1981) Acetyl coenzyme A and acetylcholine in slices of rat caudate nuclei incubated in the presence of metabolic inhibitors. J. Biol. Chem. 256: 4919-4923.

Sen, I., P. A. Grantham, and J. R. Cooper (1976) Mechanism of action of $\beta$-bungarotoxin on synaptosomal preparations. Proc. Natl. Acad. Sci. U. S. A. 73: 2664-2668.

Sgaragli, G. P., I. Sen, A. Baba, R. A. Schultz, and J. R. Cooper (1977) The mechanism of action of collagenase on the inhibition of release of acetylcholine from synaptosomal prepa- rations. Brain Res. 134: 113-123.

Simon, J. R., S. Atweh, and M. J. Kuhar (1976) Sodiumdependent high affinity choline uptake: A regulatory step in the synthesis of acetylcholine. J. Neurochem. 26: 909-922.

Stadtman, E. R. (1952) The purification and properties of phosphotransacetylase. J. Biol. Chem. 196: 527-534.

Tauc, L. (1979) Are vesicles necessary for release of acetylcholine at cholinergic synapses? Biochem. Pharmacol. 27: 34933498.

Yamamura, H. I., and S. H. Snyder (1972) Choline: High affinity uptake by rat brain synaptosomes. Science 178: 626-627. 